\title{
Three-year randomised clinical trial to evaluate the clinical performance, quantitative and qualitative wear patterns of hybrid composite restorations
}

\author{
Senthamaraiselvi Palaniappan • Liesbeth Elsen • \\ Inge Lijnen • Marleen Peumans • Bart Van Meerbeek • \\ Paul Lambrechts
}

Received: 16 December 2008 /Revised: 3 June 2009/Accepted: 30 June 2009 /Published online: 8 August 2009

(C) The Author(s) 2009. This article is published with open access at Springerlink.com

\begin{abstract}
The aim of the study was to compare the clinical performance, quantitative and qualitative wear patterns of conventional hybrid (Tetric Ceram), micro-filled hybrid (Gradia Direct Posterior) and nano-hybrid (Tetric EvoCeram, TEC) posterior composite restorations in a 3-year randomised clinical trial. Sixteen Tetric Ceram, 17 TEC and 16 Gradia Direct Posterior restorations were placed in human molars and evaluated at baseline, 6, 12, 24 and 36 months of clinical service according to US Public Health Service criteria. The gypsum replicas at each recall were used for 3D laser scanning to quantify wear, and the epoxy resin replicas were observed under scanning electron microscope to study the qualitative wear patterns. After 3 years of clinical service, the three hybrid restorative materials performed clinically well in posterior cavities. Within the observation period, the nano-hybrid and microhybrid restorations evolved better in polishability with improved surface gloss retention than the conventional hybrid counterpart. The three hybrid composites showed enamel-like vertical wear and cavity-size dependant volume loss magnitude. Qualitatively, while the micro-filled and nano-hybrid composite restorations exhibited signs of fatigue similar to the conventional hybrid composite restorations at heavy occlusal contact area, their light occlusal contact areas showed less surface pitting after 3 years of clinical service.
\end{abstract}

S. Palaniappan · L. Elsen · I. Lijnen · M. Peumans •

B. Van Meerbeek $\cdot$ P. Lambrechts $(\triangle)$

Leuven BIOMAT Research Cluster, Department of Conservative

Dentistry, School of Dentistry, Oral Pathology and Maxillo-Facial

Surgery, Catholic University of Leuven,

Kapucijnenvoer 7,

3000 Leuven, Belgium

e-mail: Paul.Lambrechts@med.kuleuven.be
Keywords Clinical performance $\cdot$ Wear . Composite restorations $\cdot$ Nano-composites $\cdot$ Micro-hybrid $\cdot$ Clinical trial

\section{Introduction}

Newer generations of hybrid composite resins with claims of improvements in filler-loading technology, filler-matrix bonding and modified resin-monomer system for posterior use are promoted nowadays. Hybrid composite resins combine colloidal silica with micro-fine glass fillers with an average particle-size diameter of around or less than $1 \mu \mathrm{m}$. Typically, these composites are loaded to $58 \%$ to $75 \%$ by volume and are radiopaque. The introduction of extremely small fillers in the micro-hybrids and nano-filled hybrids is assumed for the excellent physical properties with enhanced polishability when compared to the conventional hybrid composite resins.

An important factor affecting the intra-oral performance of posterior composite restorations in occlusal stressbearing areas is wear [1]. The aspect of wear behaviour seen clinically is a cumulative manifestation of variables like attrition, abrasion, abfraction, corrosion and fatigue, collectively defined as bio-tribo corrosion [2]. The complexity of the intraoral wear tribology of posterior composite restorations manifests clinically as loss of contour, increase in surface roughness, staining and plaque retention, structurally as microscopic alterations of surface morphology and mechanically as hygroscopic expansion, fatigue and catastrophic breakdowns. Most in vivo wear studies have generally used the subjective criteria of US Public Health Service (USPHS) to qualitatively evaluate the clinical wear performance of composites, while other in vitro studies have used the quantitative measurements of 
occlusal wear [3-5] which is extremely relevant considering posterior teeth. A very few studies [6] have investigated qualitatively the micro-morphological wear characteristics through surface morphology analysis of restorations imaged using scanning electron microscopy (SEM). Human enamel has been considered ideal as a reference material in in vivo studies and as a reference standard in in vitro studies to compare and evaluate the wear tribology of restorative materials [4]. The present study is in fact in continuation of these interests, but intends to compare the wear resistance of three different types of hybrid composites, clinically, quantitatively and qualitatively, in parallel in a 3-year randomised controlled trial study. We intend to compare a nano-hybrid (such as Tetric EvoCeram (TEC), IvoclarVivadent) and a micro-filled hybrid (such as Gradia Direct Posterior, GC) versus a conventional hybrid composite (such as Tetric Ceram) for this purpose.

The study hypotheses are (a) there are no significant differences between the clinical wear performance among the nano-hybrid (TEC), micro-filled hybrid (Gradia Direct Posterior) and the conventional hybrid (Tetric Ceram) with time, (b) the magnitude of wear generated in nano-hybrid, micro-hybrid and the conventional hybrid composite restorations would not be different from that of enamel and (c) there would be no difference in the qualitative wear patterns between the nano-hybrid, micro-hybrid and the conventional hybrid composite restorations.

\section{Materials and methods}

In this 3-year longitudinal, prospective randomised controlled clinical trial, the nano-hybrid (TEC), micro-hybrid (Gradia Direct Posterior) and the conventional hybrid (Tetric Ceram) were compared. They are listed in Table 1.

Study population Following the approval of the study protocol by the medical ethics committee, a group of 32 dental student volunteers were screened. After informed consent and complete information on the study setup and study goals, a brief clinical examination of subjects was performed for failed restorations or primary caries.

Sample size A total of 49 teeth satisfying the inclusion and exclusion criteria (Table 2) in 15 patients were selected, requiring normally three restorations per subject, but four patients received some extra restorations because of treatment need. One Tetric Ceram restoration was done on a previous endodontically treated tooth. Though endodontically treated, this tooth of the patient was in need of emergency restorative protection during the time of restoration placement, and therefore, the tooth was included.
Restoration placement Two dentists placed 49 restorations. The 49 teeth to be treated were structured in advance according to the type of restoration in two main cavity groups (class I and class II). The filling materials, TEC or Gradia Direct Posterior or Tetric Ceram, were randomised over these two cavity groups following a percent distribution of class I versus class II as 76:24 for TEC, 81:19 for Gradia Direct Posterior and 69:31 for Tetric Ceram.

A strict placement technique was followed. The restorations were placed under local anaesthesia and rubber dam. Diamond instruments in a high-speed handpiece with water spray were used to make all cavity preparations. All enamel margins were bevelled for maximum adhesive retention and optical blending using the Sonic-Sys (KaVo Company) torpedo and hemisphere diamond-coated bevel tips.

Appropriate enamel and dentin shades were selected using the Vita shade guide supplied by the study sponsor under ambient lighting condition. The teeth needing $\mathrm{CaOH}_{2}$ basing, i.e. preparations closer than $0.5 \mathrm{~mm}$ to the pulp, were covered with a glass ionomer light cured liner, before bonding procedures. Enamel and dentin conditionings were performed with a self-etching adhesive system (AdheSe for Tetric Ceram and TEC restorations, UniFil Bond for Gradia Direct Posterior restorations) of each composite resin manufacturer, according to their directions.

Placement of resin composites followed the incremental technique (2-mm-thick layers) and cured with the light (Astralis) according to the manufacturer's instruction for use. The light tip was held approximately $1.0 \mathrm{~mm}$ away from the tooth surface during curing. Details of finishing and polishing procedure are provided in Table 3.

Clinical recall At baseline, this means after 1 month of clinical service (in order to allow running-in wear for occlusal adaptation) and at subsequent recalls, every patient was insisted to brush his or her teeth immediately prior to start of the assessment. One experienced dentist rated all restorations under magnification loupes with mirror and probe subsequent to a brief soft tissue survey and recording of gingival conditions. The direct clinical evaluation of restorations was performed using the modified USPHS criteria listed in Table 4. If a parameter was judged to be clinically unacceptable, then the exact cause of failure was recorded, and it was decided whether the restoration can be repaired or requires replacement. However, the repaired restorations were still kept in the study for further recalls. Attention was paid while grading the marginal adaptation to differentiate cavomarginal discoloration, recurrent caries and marginal deterioration. Intra-oral radiographs were taken and post-operative sensitivity, if present, was also evaluated with $\mathrm{CO}_{2}$ snow (Fricar, Odontotest) and the sensitivity was scored as positive or negative. An alginate impression was made first and then a gypsum cast from 
Table 1 Description of materials used in this study

\begin{tabular}{|c|c|c|c|c|c|c|}
\hline \multirow[t]{2}{*}{ Material } & \multirow[t]{2}{*}{ Type } & \multirow[t]{2}{*}{ Polymer } & \multirow[t]{2}{*}{ Fillers } & \multicolumn{2}{|c|}{ Filler size } & \multirow{2}{*}{$\begin{array}{l}\text { Filler content } \\
\text { (\% by volume) }\end{array}$} \\
\hline & & & & Range & Mean $(\mu \mathrm{m})$ & \\
\hline Tetric Ceram & $\begin{array}{l}\text { Conventional } \\
\text { micro-hybrid }\end{array}$ & $\begin{array}{l}\text { Bis-GMA, UDMA, } \\
\text { TEGDMA }\end{array}$ & $\begin{array}{l}\text { Ba glass, } \mathrm{Ba}-\mathrm{Al} \text { fluorosilicate glass, } \\
\text { ytterbium trifluoride, dispersed } \\
\mathrm{SiO}_{2} \text { and spheroid mixed oxide }\end{array}$ & $1-3 \mu \mathrm{m}$ & 1 & 58 \\
\hline Tetric EvoCeram & Nano-hybrid & Dimethacrylate & $\begin{array}{l}\text { Ba glass, ytterbium trifluoride, } \\
\text { mixed oxide, pre-polymers }\end{array}$ & - & 0.6 & 68 \\
\hline $\begin{array}{l}\text { Gradia Direct } \\
\text { Posterior }\end{array}$ & $\begin{array}{l}\text { Micro-filled } \\
\text { hybrid }\end{array}$ & $\begin{array}{l}\text { Urethane } \\
\text { dimethacrylate } \\
\text { co-monomer matrix }\end{array}$ & $\begin{array}{l}\text { Silica, pre-polymerised fillers, } \\
\text { fluoro-alumino-silicate glass }\end{array}$ & - & 0.85 & 65 \\
\hline
\end{tabular}

which acrylic posterior custom trays were fabricated. The same custom trays were used for impression procedures at each registration session. Each restoration was documented photographically (with and without articulation paper). Impressions of restoration were made at baseline. At each recall, two impressions per air-dried, cotton-roll isolated tooth were taken with polyvinyl siloxane impression material using individualised custom trays. One impression was poured with white stone gypsum GC Fujirock EP White (Dental stone type IV, GC Europe, Leuven, Belgium) for laser scanning and another impression in Araldite D, Ciba Geigy (Belgium) for morphological observation complemented with SEM study. All replicas were uniformly trimmed and mounted on aluminium stubs for easy handling and repositioning.

Wear evaluation The gypsum replicas were scanned threedimensionally using a 3D laser scanner that uses a light line produced by a laser diode and an optical setup with a cylindrical lens (100,000 surface points per sample; accuracy $5 \mu \mathrm{m}$ ). The lateral displacement of the laser beam on reflection from the object, corresponding to the height $(Z)$ at each surface point, was detected by a charge-coupled device chip. The grey scanned baseline images were then super-imposed automatically, and the images at 6, 12, 24 and 36 months were subtracted from baseline with Match$3 \mathrm{D}$, specially developed image analysis software (volume, mean vertical loss, $0.5 \%$ quantiles). This digital subtraction resulted in a differential image used to quantify the wear magnitude. Based on the blue articulation spots in the clinical pictures at baseline and at the different recall sessions, the following wear facets were identified on the difference image: occlusal contact area on enamel (OCAE)-heavy and light, occlusal contact area on composite (OCAC), differential wear (shared OCAE and OCAC), contact-free occlusal area (CFOA) and restoration margins. Using the zoom function and the cursor, the $Z$ value of 15 points were noted for each of the aforementioned spots. The maximum and minimum values wear excluded. The mean of the remaining eight values was taken to be the vertical loss of the wear facets. The deepest wear point in the most deteriorated area on the margin of each of the restorations

Table 2 Inclusion and exclusion criteria for patient selection

\begin{tabular}{ll}
\hline Inclusion criteria & Exclusion criteria
\end{tabular}

Have a need for two posterior tooth coloured restorations

A medical history that will not complicate the outcome of the results

Have a history of brushing his/her teeth at least once a day

The subject should have a low to moderate caries rate, normal periodontal status with good home care and possess an uncompromised dentition

Subjects who have natural dentition directly opposing the test restoration. Exceptions are made if the opposing dentition is a gold crown

Only vital teeth with a normal appearance on the radiograph, normal response to palpation, percussion and a favourable response to cold stimulus will be selected

Patient needing class I or class II restorations in posterior teeth. First and/or second mandibular and/or maxillary molar
Individual with a chronic disease with oral manifestations

Individual who exhibit gross oral pathology, poor oral hygieneor poor dental health

Individual with gross dental caries or severe periodontal problems that could compromise the future of the tooth

Subjects with allergy to any materials to be used in the study

Individual who exhibit signs or symptoms of severe bruxism

Subject with porcelain directly opposing the test restoration

Teeth that will be used as an abutment for removable or fixed partial dentures will be excluded 
Table 3 Details of finishing and polishing procedures

\begin{tabular}{|c|c|c|c|c|}
\hline & Duration & Speed & Conditions & Manufacturers \\
\hline Finishing diamond bur kit $(4,092.314)$ & & & & Komet GmbH, Germany \\
\hline Fine grit (30 m; DETF) & 30 & 140,000 & Wet (water spray) & \\
\hline Extra-fine grit (15 m; DETF) & 30 & 140,000 & Wet (water spray) & \\
\hline Sof-Lex (XT) discs & & & & 3M Espe, Germany \\
\hline Medium (orange; $2382 \mathrm{M}$ ) & 10 & 20,000 & Dry & \\
\hline Fine (light orange; 2382F) & 10 & 20,000 & Dry & \\
\hline Extra fine (yellow; 2382SF) & 10 & 20,000 & Dry & \\
\hline Sof-Lex strips & & & & 3M Espe, Germany \\
\hline Coarse/medium $(1,954)$ & 10 & 20,000 & Dry & \\
\hline Occlubrush assortment $(2,520)$ & 10 & 20,000 & & \\
\hline Regular/small/point & 10 & 20,000 & & Kerr, Switzerland \\
\hline Polishing kit (4312A.204) & 10 & 20,000 & Dry & Komet GmbH, Germany \\
\hline Medium (pink) & 10 & 20,000 & Dry & \\
\hline Fine (grey) & 15 & 20,000 & Dry & \\
\hline Prisma gloss paste on polishing cup & 20 & 20,000 & Dry & Dentsply, Germany \\
\hline Prisma gloss extra-fine paste on polishing cup & 20 & 20,000 & Dry & Dentsply, Germany \\
\hline
\end{tabular}

was measured as the maximum vertical loss along the margin, the shallow point as the minimal vertical loss. The average of 15 points on the localised, deteriorated margins was recorded as mean vertical loss of marginal degradation. The number of surface points along the grey scanned image was recorded as total surface area. Using the edit function, the area with restoration and the surrounding unrestored enamel surface were separately defined manually on each grey scanned image of baseline and recall. Once the restoration and the cavosurface were separated, the Match 3D software calculated the surface area of restoration and surface area of enamel. Using the statistic mode of the difference images, the volumetric wear along the total occlusal surface (restored surface + enamel) was determined in cubic millimetre as total surface volume loss (TSV loss), restorative surface volume loss (RSV loss) and enamel surface volume loss (ESV loss).

Statistical analysis was performed with Statistica (version 8.0) for the clinical USPHS data and the wear quantification data. Sign test provided the comparative statistical analysis of the materials over the study period. For each evaluated USPHS criterion of each material group, further analysis was done using the Friedman ANOVA (by ranks) and Kendall's concordance test for changes from baseline to 6-, 12-, 24- and 36-month data. The McNemar's test assessed the statistical significance of the changes in lower ranking criteria. The level of significance was set at $p \leq 0.05$ for all tests. In addition to ranking, the vertical loss, volume loss and differential wear rates of materials are compared with that of referenced enamel for inferring the statistical significance for the observed differences in rating the clinical wear performance as acceptable or unacceptable. The correlation coefficient $(r)$ was calculated for the paired vertical and volume loss data to determine whether a relationship exists between them.

SEM evaluation The epoxy replicas were gold sputtered, subjected to high magnification dental surgical optical microscopy (OPMI Pro ergo, Carl Zeiss surgical GmbH, Oberkochen, Germany), prior to SEM imaging, in order to downsize the samples for SEM view. The potential samples demonstrating interesting micro-morphologic features such as defined wear facets, differential wear steps, degrading margins and fractures were further explored under SEM. Quadrant-wise photomicrographs of each sample was made initially followed by thorough scanning area by area up to the magnification of 200 .

\section{Results}

The present study covers the recall periods of baseline, 6 , 12, 24 and 36 months.

\section{Clinical evaluation-USPHS qualitative analysis}

Three years after placement, 16 Tetric Ceram, 17 TEC and 16 Gradia Direct Posterior restorations could be evaluated and scored according to the USPHS criteria. The overall clinical recall success rate of restorations at 3 years recall was $100 \%$ (49 of 49 restorations) with no dropouts and no 
Table 4 Modified USPHS criteria for the direct clinical evaluation of the restorations

\begin{tabular}{|c|c|}
\hline Category & Rating and characteristics \\
\hline Anatomical form & $\begin{array}{l}\text { A: Restoration's contour is continuous with existing anatomical form and margins } \\
\text { B: Restoration is slightly over contoured or under contoured } \\
\text { C: Marginal overhang or tooth structure (dentin or enamel) is exposed } \\
\text { D: Restoration is missing, traumatic occlusion or restoration causes pain in tooth or adjacent tissue }\end{array}$ \\
\hline Secondary caries & $\begin{array}{l}\text { A: No visible caries } \\
\text { C: Caries contiguous with the margin of the restoration }\end{array}$ \\
\hline Colour match & $\begin{array}{l}\text { A: No mismatch in colour, shade or translucency between restoration and adjacent tooth structure } \\
\text { B: Mismatch between restoration and tooth structure within the normal range of tooth } \\
\text { C: Mismatch between restoration and tooth structure outside the normal range of tooth } \\
\text { D: Aesthetically displeasing colour, shade and translucency }\end{array}$ \\
\hline Retention & $\begin{array}{l}\text { A: Present } \\
\text { B: Partial loss } \\
\text { C: Absent }\end{array}$ \\
\hline Marginal adaptation & $\begin{array}{l}\text { A: Excellent continuity at resin-enamel interface; no ledge formation, no discoloration } \\
\text { B: Slight discoloration at resin-enamel interface; ledge at interface } \\
\text { C: Moderate discolouration at resin-enamel interface measuring } 1 \mathrm{~mm} \text { or greater } \\
\text { D: Recurrent decay at margin }\end{array}$ \\
\hline Polishability & $\begin{array}{l}\text { A: Smooth and highly shiny, similar to enamel } \\
\text { B: Smooth and satin, highly reflective } \\
\text { C: Rough and shiny, satin, somewhat reflective } \\
\text { D: Rough and dull or satin, not reflective }\end{array}$ \\
\hline Surface staining & $\begin{array}{l}\text { A: Absent } \\
\text { C: Present }\end{array}$ \\
\hline Sensitivity & $\begin{array}{l}\text { Preoperative sensitivity (yes/no) } \\
\text { Post-operative sensitivity (yes/no) }\end{array}$ \\
\hline Soft tissue health & $\begin{array}{l}\text { A: Excellent response, no inflammation } \\
\text { B: Slight inflammation of gingival tissue } \\
\text { C: Moderate to severe gingival inflammation }\end{array}$ \\
\hline Proximal contact points & $\begin{array}{l}\text { A: Present } \\
\text { C: Absent }\end{array}$ \\
\hline
\end{tabular}

$A$ alpha, $B$ bravo, $C$ charlie, $D$ delta

major material-related casualties that needed restoration replacement over the 3-year study period.

Between the date of placement and the baseline followup, one TEC restoration (MOD) had to be partially removed for the endodontic occlusal access cavity in order to perform root canal treatment of pulpitis symptoms. This tooth was originally filled with a deep mesio-occluso-distal Amalgam restoration and had shown unstable pulp conditions before it was restored with TEC. The occlusal endodontic access cavity has been restored with the same TEC material and finished in a minimal invasive way. As the procedure was done before the baseline session, the total restoration was included in the study.

None of the restorations failed due to secondary caries, post-operative sensitivity and bulk or catastrophic fractures within the observation period of 3 years, contributing to
$100 \%$ retention rate. The results of the clinical evaluation of 49 restorations at baseline, 6, 12, 24 and 36 months are shown in Tables 5, 6 and 7, with the percentage of alpha scores at 36 months plotted in Fig. 1. There were no statistically significant differences found between the three types of restorative materials with regard to anatomical form, retention, secondary caries, gingival health, postoperative sensitivity and loss of proximal contact points $(p>0.05)$.

The Friedman ANOVA and Kendall's concordance test reported that the mean alpha score values are significantly different ( $p=0.021)$ among the criteria (in percentage) from baseline to $6,12,24$ and 36 months. The rank analysis revealed lowest ranks to three criteria. The ranking order was polishability $<$ marginal adaptation $<$ colour match, based on their mean alpha values. The sign test exhibited 


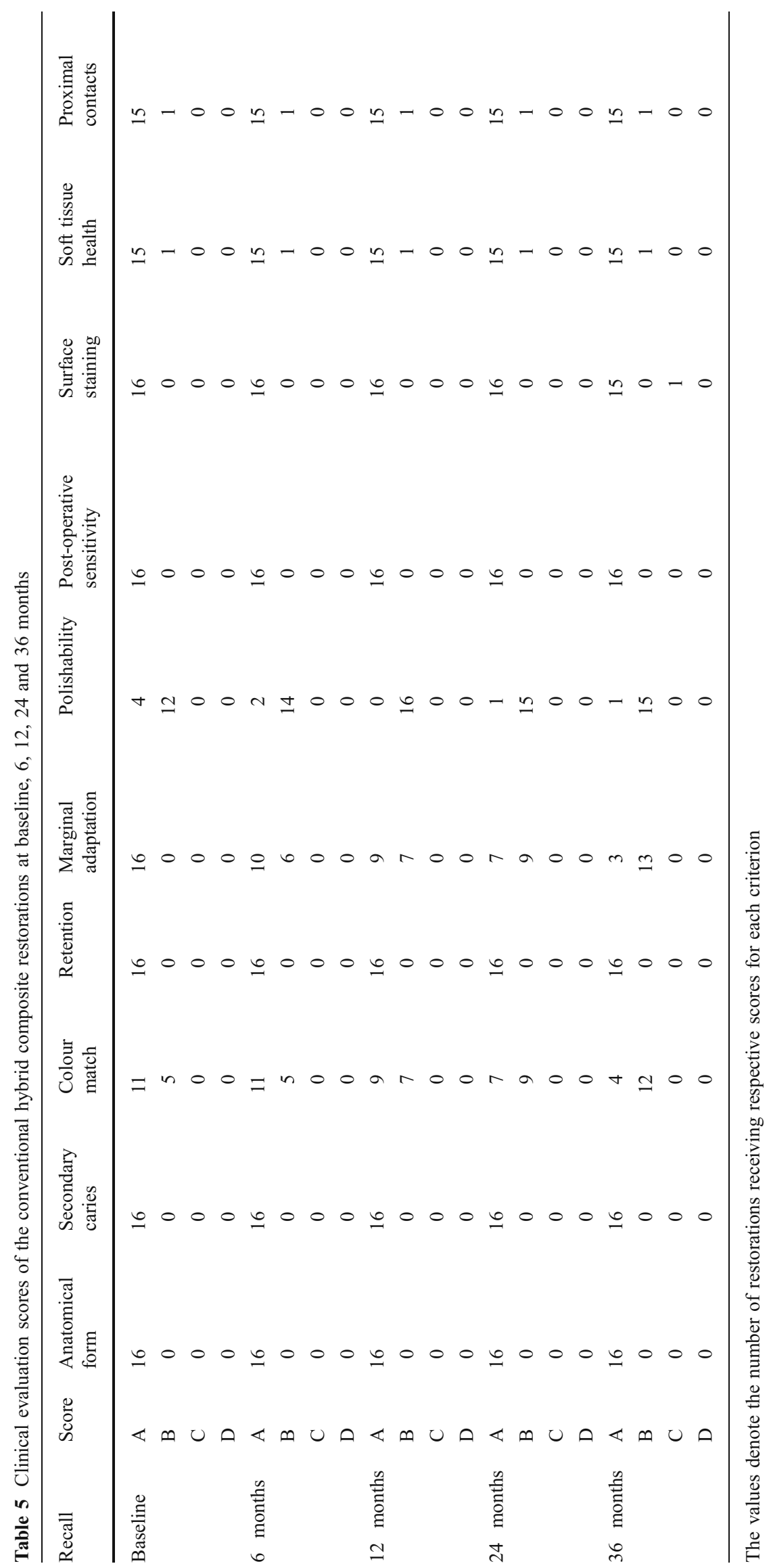




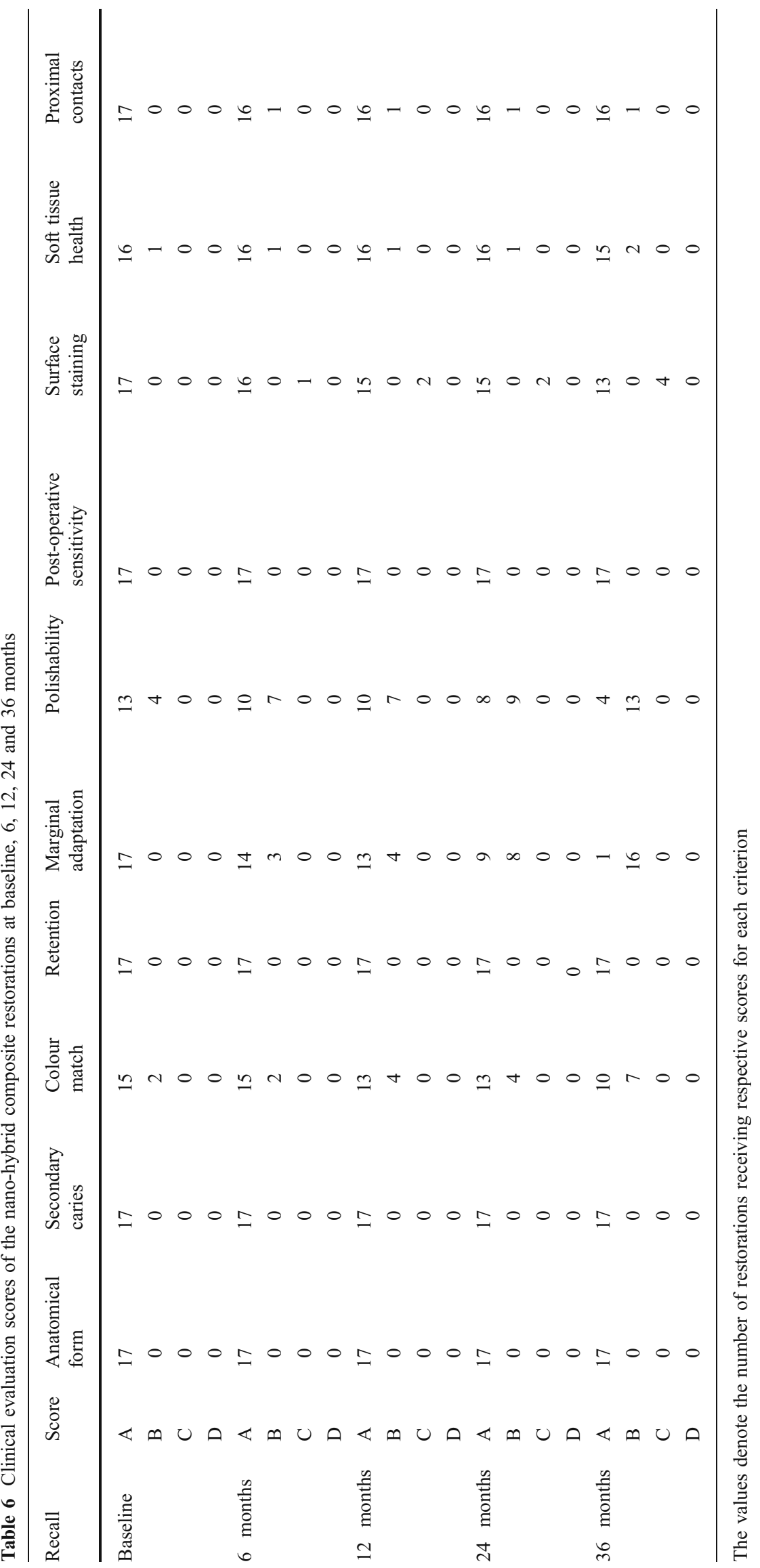




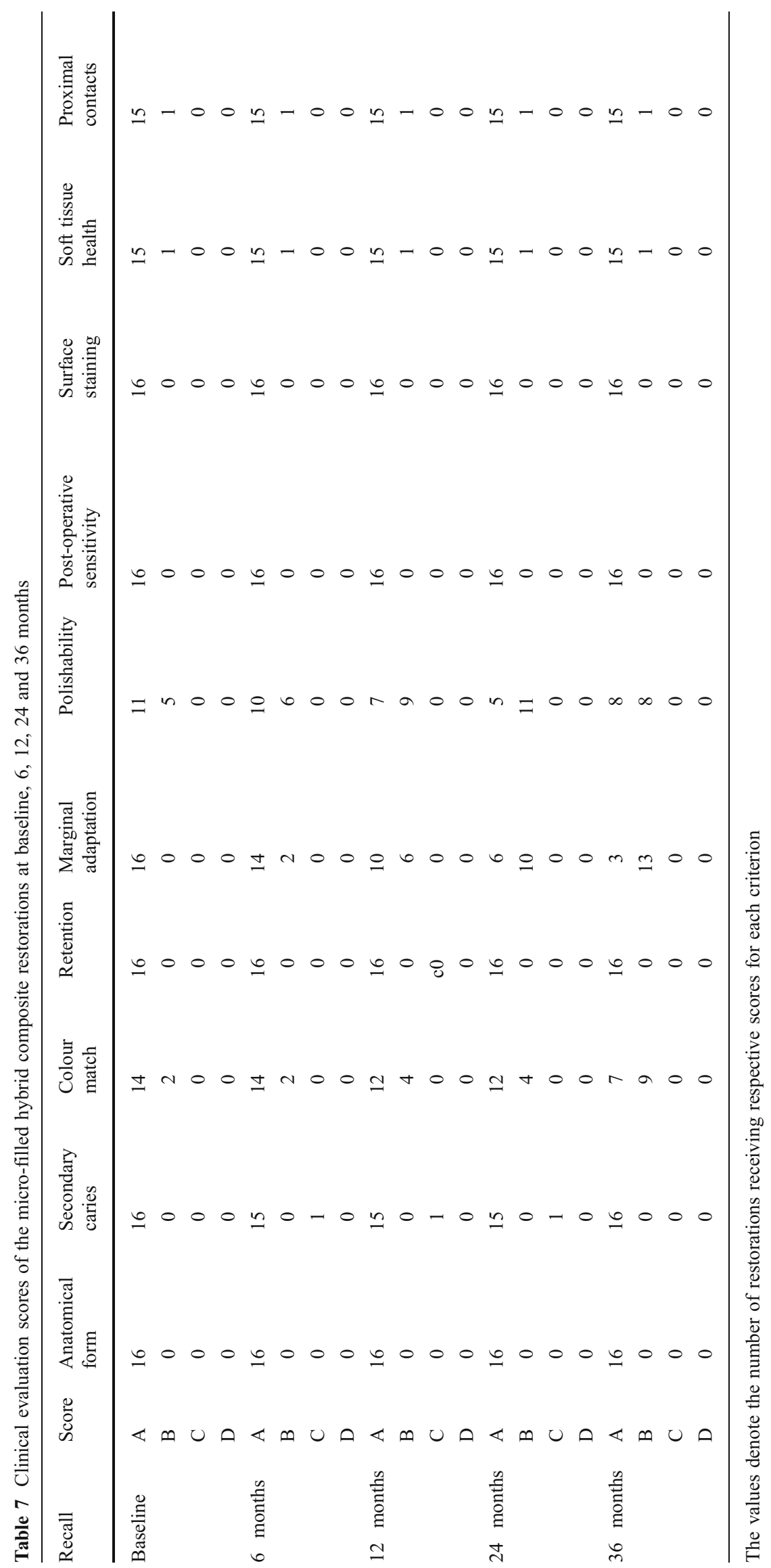


Fig. 1 Percentage alpha ratings of evaluated restorations at 36-month recall. The percentage of alpha scores of each criterion between the different hybrid composite restorations at 36-month recall. $A F$ anatomic form, $S C$ secondary caries, $C M$ colour match, $R E T$ retention, $M A$ marginal adaptation, $P O L$ polishability, $S S$ surface staining, $S T H$ soft tissue health, $P O S$ post-operative sensitivity, $P C P$ proximal contact points

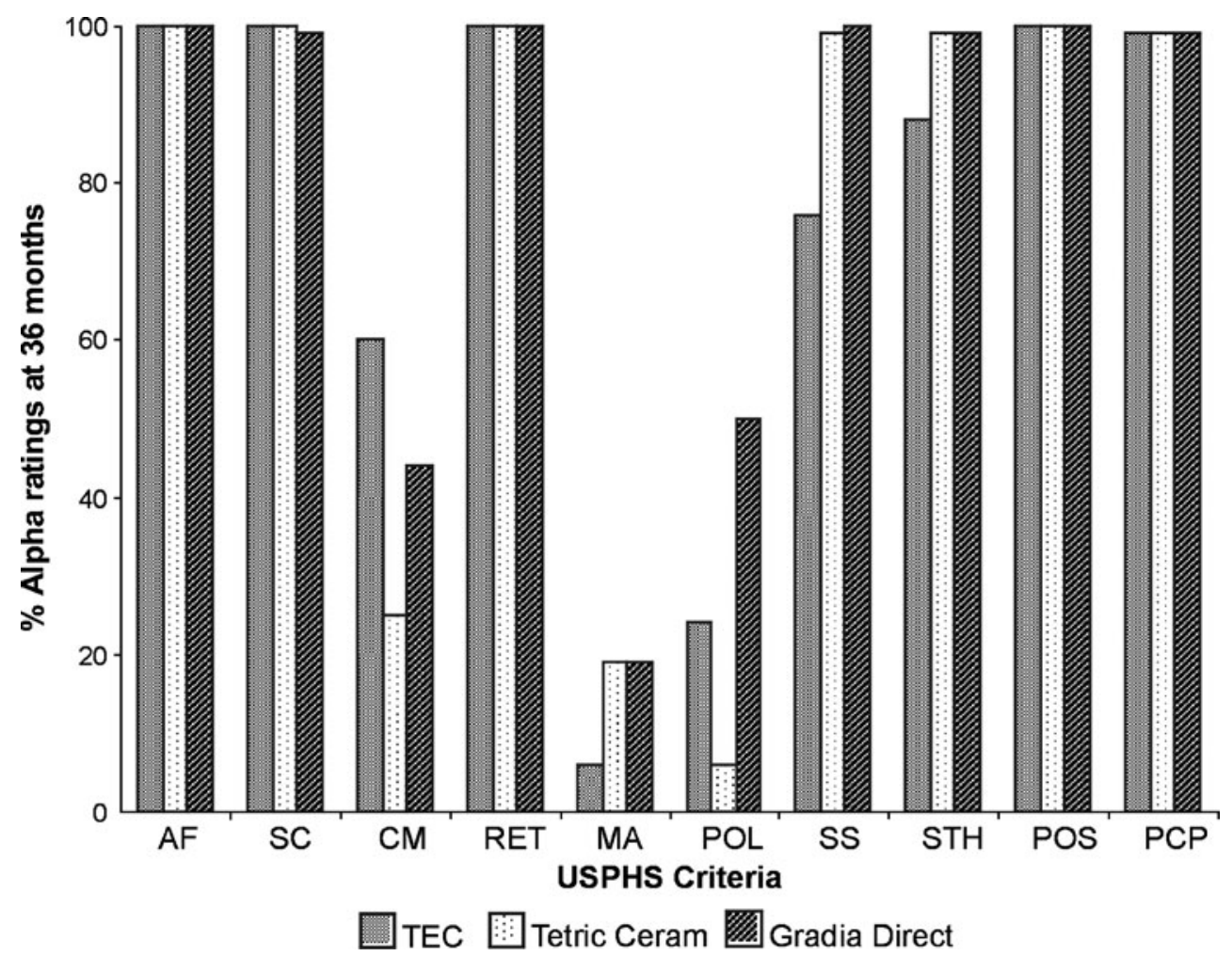

for Gradia Direct Posterior (50\% alpha) a significantly better polishability than for TEC ( $24 \%$ alpha; $p=0.002)$ and Tetric Ceram (6\% alpha; $p=0.006)$ composite restorations after 36 months. Evaluation of the criterion "colour match" at the 3-year recall showed for TEC a significantly better colour match $(60 \%$ alpha) compared with Tetric Ceram (25\% alpha; $p=0.021)$ and Gradia Direct Posterior $(44 \%$ alpha; $p=0.035$ ) composite restorations.

All restorations were rated alpha for the parameter 'marginal adaptation' at baseline. However, after 1-year recall, most of the restorations were rated bravo, and at the 3 -year evaluation, just $6 \%$ of TEC, $19 \%$ of Tetric Ceram and $19 \%$ of Gradia Direct Posterior restorations scored alpha. The marginal integrity of the restorations showed predominantly bravo scores for all the three types of composite restorations, due to the presence of several small, discontinuous enamel fractures along the restoration margins, chipping of the filling material from the marginal ridge or/and a gap along the cavosurface margin. All of the above chipped areas and fractures were rated bravo. The bravo-rated restorations were neither repaired nor excluded from further evaluation, since the fractures did not impair their functioning or gingival health.

At the 3 -year recall, $76 \%$ of the TEC, $99 \%$ of Tetric Ceram and $100 \%$ of the Gradia Direct Posterior restorations were rated as alpha for surface staining. Moderate surface staining was detectable also on other teeth, but not aesthetically unacceptable and could easily be removed without complex prophylactic measures. All teeth subjected to restoration responded positively to the vitality testing, throughout the recall period of 36 months. None of the patients reported complaints requiring replacement of restorations.

Careful comparison of the clinical photographs revealed firm occlusal contact areas (OCAs) at their marginal ridges and were associated with minor occlusal-proximal marginal chippings. However, there were no subjective complaints of food impaction and no other restorations were recorded as having lost their contact area after 3 years.

\section{D laser scan quantitative analysis}

A distinction was made between the vertical loss at OCAs by antagonistic teeth and the volume loss along the total occlusal surface.

Vertical loss in height From baseline up to 36 months for 49 restorations, the mean and standard deviation (SD) values for the cumulative mean vertical loss of enamel (heavy and light) and the three materials are shown in Table 8 and Fig. 2a. No statistically significant higher cumulative vertical loss mean wear was observed with any of the three evaluated materials versus enamel at heavy OCAs throughout the recall period of 36 months $(p>0.05)$. In addition, none of the three materials showed statistically significant difference in the vertical wear versus any of the other evaluated materials along the entire recall period ( $p>$ $0.05)$. The differential wear calculated as the difference in the mean vertical loss of every material with the mean 
Table 8 Mean and SD of the measured vertical loss (micrometre)

Fig. 2 Mean vertical and volume loss of enamel and composites at different recalls. The change in the a vertical and $\mathbf{b}$ volume loss magnitude between enamel and the composites over the study period is plotted

\begin{tabular}{lllll}
\hline Materials & 6months (SD) & 12months (SD) & 24months (SD) & 36months (SD) \\
\hline Enamel (heavy OCA) & $-36(16)$ & $-54(20)$ & $-76(22)$ & $-107(25)$ \\
Enamel (light OCA) & $-17(4)$ & $-21(4)$ & $-38(10)$ & $-56(12)$ \\
Tetric Ceram & $-46(13)$ & $-61(17)$ & $-81(21)$ & $-99(28)$ \\
Tetric EvoCeram & $-43(14)$ & $-54(17)$ & $-67(22)$ & $-81(23)$ \\
Gradia Direct Posterior & $-49(16)$ & $-72(28)$ & $-98(38)$ & $-125(45)$ \\
\hline
\end{tabular}

a

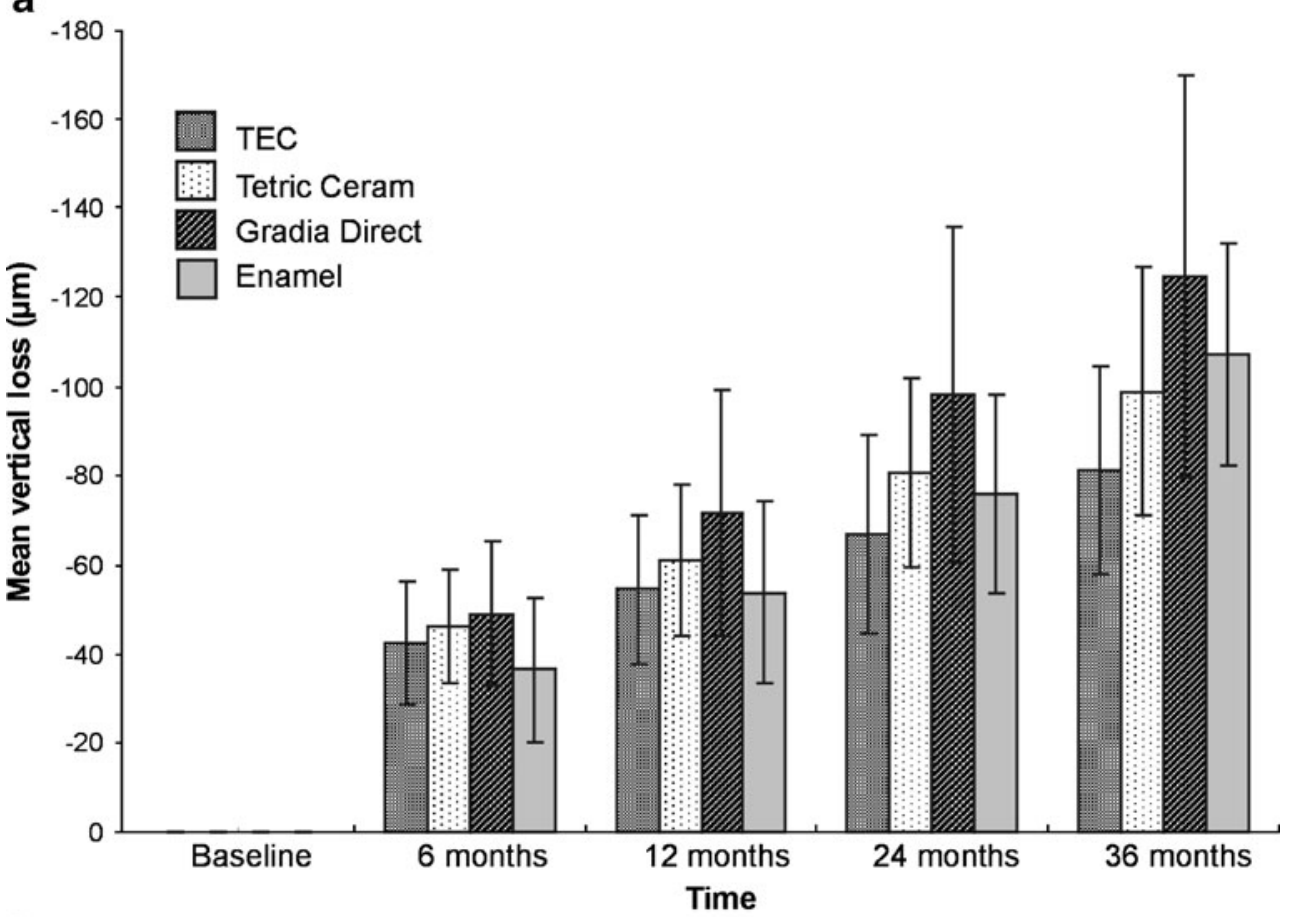

b

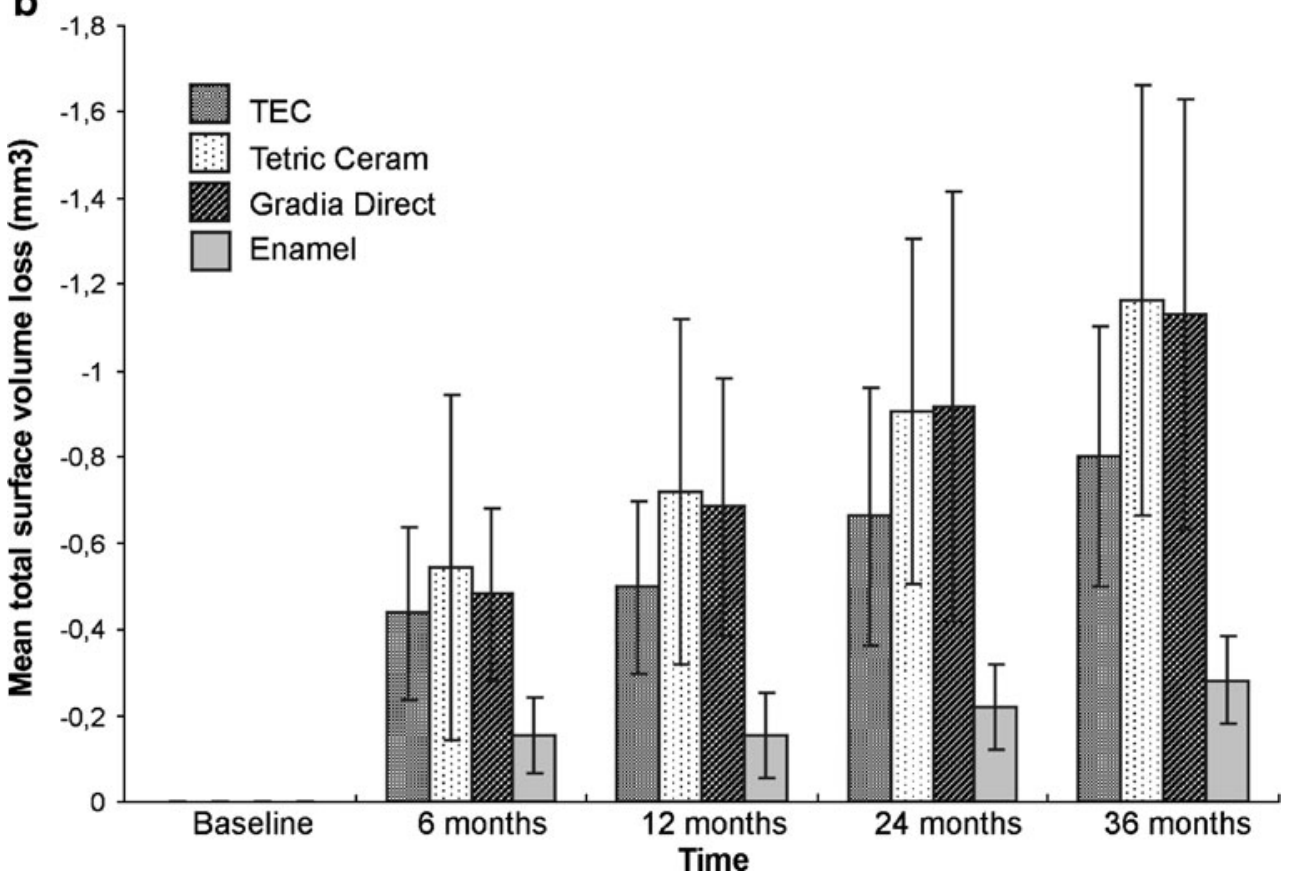


vertical loss of enamel in every patient is plotted in Fig. 3a. Only the graph at 36 months is shown, since it was not different from the graphs of other recall periods. Vertical loss values of areas with chipped overhangs are not reported, as the overhang fracture occurs in a different manner than that occurring in restored regions.

Volume loss For all the recall periods, the RSV loss and the ESV loss, both contributing to the measured TSV loss, are shown in Table 9 and Fig. 2b. Figure $3 b$ represents the differential volume loss magnitude of enamel and composites in each of the 15 subjects of the study population. The volume loss of the three different hybrid composites (RSV) remained significantly higher $(p>0.05)$ than enamel (ESV). The mean, minimal and the maximal loss of each material along the restoration margins at the 36-month recall are shown in Table 10. No statistically significant differences were observed with the sign test among the three materials $(p>0.05)$. There was a strong correlation between vertical and volume loss; this correlation was highly significant $\left(r^{2}=0.99\right.$ for Tetric Ceram, TEC and Gradia Direct Posterior; $p=0.0001$; Fig. 4). A line of best fit to the correlated data indicates a linear relationship between vertical and volume loss of restorations.
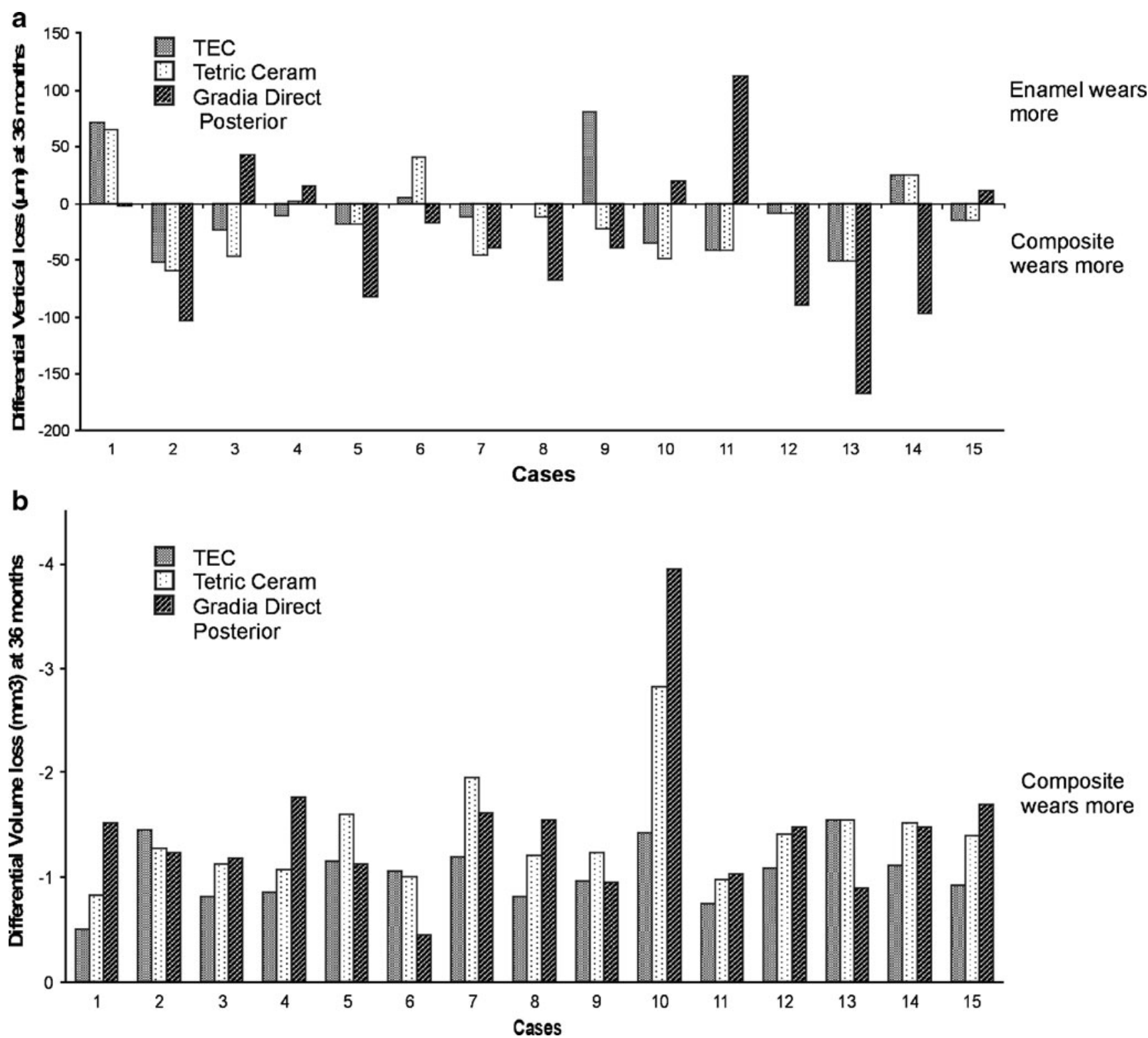

Fig. 3 Differential vertical and volume loss between enamel and the composites among the 15 individuals of the study population at 36 months. In a, the difference in the vertical loss magnitude of enamel and composites at shared occlusal contact areas are plotted in each of the 15 subjects of the study population. b The difference in the volume loss magnitude of enamel and composites in each of the 15 subjects of the study population 
Table 9 Mean and SD of the measured volume loss (cubic millimetre)

\begin{tabular}{llll}
\hline & TEC (SD) & Tetric Ceram (SD) & Gradia Direct Posterior (SD) \\
\hline 6 months & & & \\
TSV loss & $-0.590(0.2)$ & $-0.669(0.4)$ & $-0.664(0.2)$ \\
RSV loss & $-0.437(0.2)$ & $-0.545(0.4)$ & $-0.482(0.2)$ \\
ESV loss & $-0.153(0.1)$ & $-0.125(0.1)$ & $-0.182(0.2)$ \\
12 months & & & \\
TSV loss & $-0.676(0.2)$ & $-0.842(0.3)$ & $-0.849(0.3)$ \\
RSV loss & $-0.498(0.2)$ & $-0.719(0.4)$ & $-0.685(0.3)$ \\
ESV loss & $-0.178(0.2)$ & $-0.123(0.1)$ & $-1.207(0.6)$ \\
24 months & $-0.894(0.3)$ & $-1.046(0.4)$ & $-0.916(0.5)$ \\
TSV loss & $-0.662(0.3)$ & $-0.907(0.4)$ & $-0.291(0.4)$ \\
RSV loss & $-0.231(0.1)$ & $-0.139(0.4)$ & $-1.542(0.8)$ \\
ESV loss & & & $-1.125(0.5)$ \\
36 months & $-1.116(0.3)$ & $-1.492(0.5)$ & $-0.410(0.5)$ \\
TSV loss & $-0.802(0.3)$ & $-1.201(0.5)$ & \\
RSV loss & $-0.301(0.2)$ & $-0.205(0.2)$ & \\
ESV loss & & & \\
\hline
\end{tabular}

\section{SEM evaluation}

The SEM evaluation of the resin replica restorations demonstrated the occlusal surface alterations and the qualitative wear patterns. The qualitative wear patterns of one representative one conventional hybrid, one nanohybrid and one micro-filled hybrid composite restoration is shown in Figs. 5, 6 and 7, respectively. Overall, three patterns of wear were evident: cyclic fatigue at heavy OCA (Fig. 5d-f for Tetric Ceram; Fig. 6d-f for TEC; Fig. 7d-f for Gradia Direct Posterior), pitting at light OCA (Fig. $5 \mathrm{~g}-\mathrm{i}$ for Tetric Ceram; Fig. 6g-i for TEC; Fig. 7g-i for Gradia Direct Posterior) and scratches/striations at CFOA (Fig. 5j1 for Tetric Ceram; Fig. 6j-1 for TEC; Fig. $7 \mathrm{j}-1$ for Gradia Direct Posterior) along the food escape pathways. Compared to TEC and Gradia Direct Posterior, the majority of light OCAs of Tetric Ceram restorations exhibited less surface smoothness at baseline and 6 months (Fig. 5g). The surface irregularities of these restorations remained progressively pronounced until 36 months of clinical service (Fig. 5i). At high impact (heavy) occlusal contact areas shared by enamel and composite, approximately $55 \%$ of all restorations suffered from localised marginal fractures in less than two fourth of the marginal circumference (Figs. 5b, 6b and 7b) and fatigue crack growth at areas adjacent to the fractured margins at 12 months (Figs. 5d, 6d and 7d). At 24 months (Figs. 5e, 6e and 7e), while the margins were progressively degrading, the fatigue cracks propagated resulting in fatigue fracture at 36 months (Figs. 5f, 6f and 7f).

At baseline (Figs. 5a, 6a and 7a), the majority of restorations had excess composite material as overhangs mainly in pits, fissures and around the bevelled enamel margins. Within 1 year of clinical service, these overhangs fractured as standalone in $70 \%$ of teeth in our study. In the remaining $20 \%$, overhang fracture was associated with cavosurface margin opening (Fig. 6f) or margin fracture (Fig. 5f).

\section{Discussion}

\section{Clinical performance}

The clinical assessment of the loss of anatomical form of restorations is essentially an indication of the proportion of the restored surface exhibiting morphological alterations due to the wear. Based on the steady state of the alpha scores of the criteria anatomic form and retention in almost all restorations throughout the study period, it is suggestive that the effect of wear on the restoration morphology and retention was small and macroscopically barely visible to the naked eye. Therefore, all the three hybrid composites have evolved smoothly in time regarding the anatomic form and retention.

The technique of incremental filling of composites adopted in this study to reduce the shrinkage stress and micro-leakage at the adhesive interface, as suggested by [7], and the better oral hygiene status of the patients could justify the absence of failures due to secondary caries after 36 months. The time and attention devoted to the restoration placement techniques and the clinically acceptable mechanical properties of the restorative materials that minimise the hydrostatic dentin fluid movements might explain the lack of post-operative sensitivity after 36 months in the present study. This has also been addressed in a 
number of studies [8-10]. Ninety-nine percent of the cases recorded as not having lost the inter-proximal contact in the present study could be explained with the special attention given to the appropriate use of the matrix in building up the critical area of the marginal ridge of the proximal part of the restoration. In the remaining $1 \%$ of cases, all the three hybrid restorative materials were susceptible to cyclic stress resulting in occlusal-proximal marginal fractures, weakening the proximal contact points in the evolving period of 36 months.

Slightly rougher surface with moderate staining was observed in very few cases of all the three materials after 36 months. This could be mainly due to the friction with food and antagonist teeth during mastication. In addition, from baseline to 36 months, the progressively decreasing alpha scores of colour match for all the three hybrid restorative materials could also be related to pigment absorption of the rough restorative surfaces from dietary habits. However, the evolution of colour mismatch between the restoration and the tooth structure was within the normal range of tooth colour and the colour stability of all the three hybrid materials was acceptable after 3 years of clinical service. Nevertheless, the colour mismatch between the surrounding tooth structure and the restoration is a rather subjective observation because of lighting conditions, chameleon effects and surface staining.

The polishability of Tetric Ceram was not only significantly worse than TEC and Gradia Direct Posterior at 36 months, but significantly worst $(p=0.0156)$ over time from baseline to 36 months. This is suggestive that the differences in filler sizes between the three restoratives might have led the nano-hybrid and micro-hybrid material to be better evolved in polishability with improved surface gloss retention than the conventional hybrid counterpart. The marginal degradation scores were quite similar for TEC, Tetric Ceram and Gradia Direct Posterior used in the present study.

The recall rate in this study One hundred percent is in accordance with that in other clinical trials of micro-hybrid and nano-composites (59-100\% recall rate) [11-13]. TEC, Tetric Ceram and Gradia Direct Posterior restorations did not differ in their susceptibility to marginal degradation throughout the study. For comparable observation periods but with different micro-hybrid composites, most studies [11-13] have reported similar deterioration of marginal integrity due to factors such as shrinkage stress, the effect of cavity geometry on C-factor [14, 15], butt-joint occlusal margin and self-etch adhesives. The failure rate of $0 \%$ observed in this 3year study is within the range of $0 \%$ to $45 \%$ annual failure rates reported in systematic reviews on clinical trials assessing the longevity of posterior composite restorations 


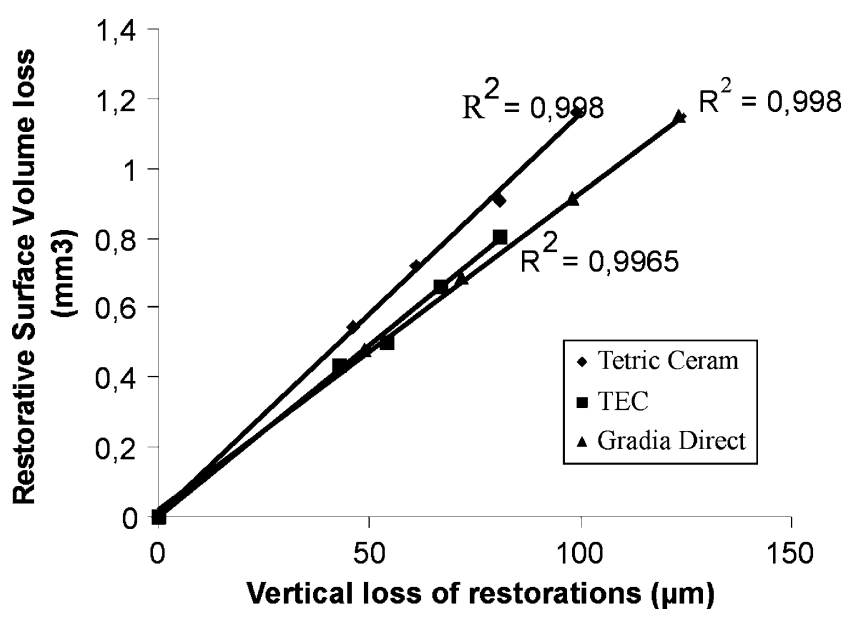

Fig. 4 Graph of correlation between vertical loss and volume loss of restorations. $r^{2}=0.998$ for Tetric Ceram, $r^{2}=0.996$ for Tetric Ceram and $r^{2}=0.998$ for Gradia Direct Posterior

$[1,16]$. While several studies are available in literature demonstrating the acceptability of conventional hybrid (Tetric Ceram) composite in posterior stress bearing areas, only a very limited number of clinical trials have reported the clinical performance of the novel micro-hybrid (Gradia Direct Posterior) and nano-hybrid (TEC) composites.

\section{Quantitative wear performance}

The enamel-like wear is necessary for composites, as they should simulate the properties of enamel and dentine [17]. As time evolved during clinical service, all the three hybrid restoratives underwent a running-in wear period followed by the steady state/stabilisation period [3]. The absence of significant difference in the OCA wear/ vertical loss magnitude of the three hybrid composite restorations versus enamel, until 36 months recall, has conferred an enamel-like wear resistance to the three hybrid composites.

The significantly increased volume loss of the restorative materials (RSV loss) versus enamel (ESV loss) over time could be attributed to the difference in proportion of restorative surface area versus the surrounding enamel surface area. This confirms the hypothesis that the greater the dimensions of restorations, the larger the amount of surface area exposed to the masticatory stresses and the faster the restoration will undergo loss of material $[3,18]$. The mean occlusal wear volumes of ceramic crowns for molars were $0.34 \pm$ $0.08 \mathrm{~mm}^{3}$ after 1 year [19]. This wear volume is lesser than of the three restoratives in the present study. The difference in hardness between the veneering materials and the composite restoratives could explain the difference in the wear volume. The linear relationship between vertical and volume loss is suggestive that vertical wear is directly proportional to volumetric wear over time. Such correlation has already been demonstrated for in vitro wear data quantified using profilometry (Perthometer) and optical sensors (FRT MicroProf) [20].

The evolving material loss along the cavosurface margins appeared to occur regardless of the type of restorative material. Nevertheless, it is not impossible that the application of self-etching primer bonding system might have lead to a compromise concerning adhesion to the cavosurface margins. In vitro studies have shown that self-etching adhesive systems and the all-in-one adhesives were less effective than total etch systems concerning dentin and enamel bond strength [21-23]. The present study did not evaluate the effectiveness of the adhesive system regarding the criteria of marginal adaptation, which was not its objective.

\section{Qualitative wear performance}

The surface appearance of hybrid composite resin wear facets at heavy OCAs assessed qualitatively under SEM revealed fatigue crack propagation, irrespective of the type of the hybrid composite. This is suggestive that none of the evaluated hybrid composite resin restorations could sustain the fatigue induced by the cyclic stress during mastication. The light OCAs of the three hybrid resin composite restorations were susceptible to pitting over time. However, the severity of pitting was lesser in the nano-composite and the micro-hybrid resin restorations due to their smaller filler particles. In addition to the pitting micro-wear, fine scratches or striations of different length were evident along the food escape pathways of the occlusal surfaces of almost every restoration. The striation pattern has previously been reported in human enamel due to prophylaxis [24], fossil hominids and non-human primates [25-27] reflecting the impact of coarse particles and foreign body in dietary constituents. Anthropological studies have proved that striations are clear enamel imprints left by the abrasives in the food and masticatory action [28, 29]. However, to the authors' knowledge, no such pattern has been reported in restored surfaces to date.

\section{Conclusions}

After 3 years, the three hybrid restorative materials performed clinically well in posterior cavities with no observable catastrophic fractures. The nano-hybrid and micro-filled hybrid restorations showed enamel-like vertical wear and cavity-size dependant volume loss magnitude. While the qualitative wear pattern of the micro-filled and nano-hybrid composite restorations was the same as the conventional hybrid composite restorations at heavy OCAs, 

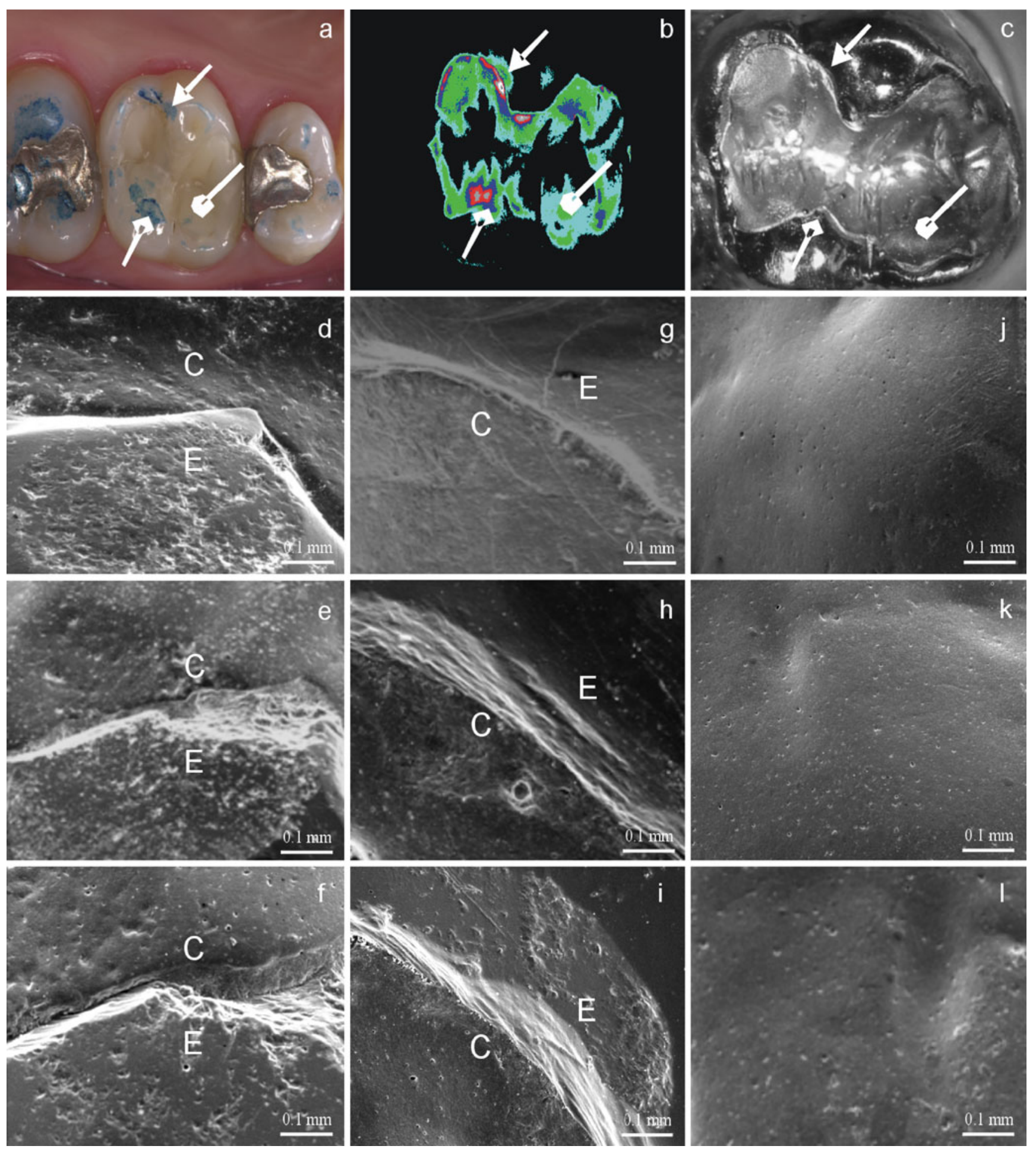

Fig. 5 A representative conventional hybrid composite restoration. This figure includes a representative clinical picture (a), difference image (b) and SEM photomicrographs (c-l) of wear spots in a conventional hybrid composite restoration over the study period. a Clinical, occlusal view of a Tetric Ceram restoration in 26 with registered wear spots. $\longrightarrow$ = light occlusal contact area; $\longrightarrow$ = heavy
OCA $\longrightarrow \longrightarrow=$ contact-free occlusal area. $\mathbf{b}$ Difference image at 36 months is shown to enable a better differentiation of the wear spots. (c) Micro-morphological overview at 6 months under magnification $(\times 15)$, higher magnification $(\times 150)$ of heavy OCA at $12($ d), $24($ e) and 36 months (f); light OCA at 12 (g), 24 (h) and 36 months (i); CFOA at $12(\mathbf{j}), 24(\mathbf{k})$ and 36 months (l) 

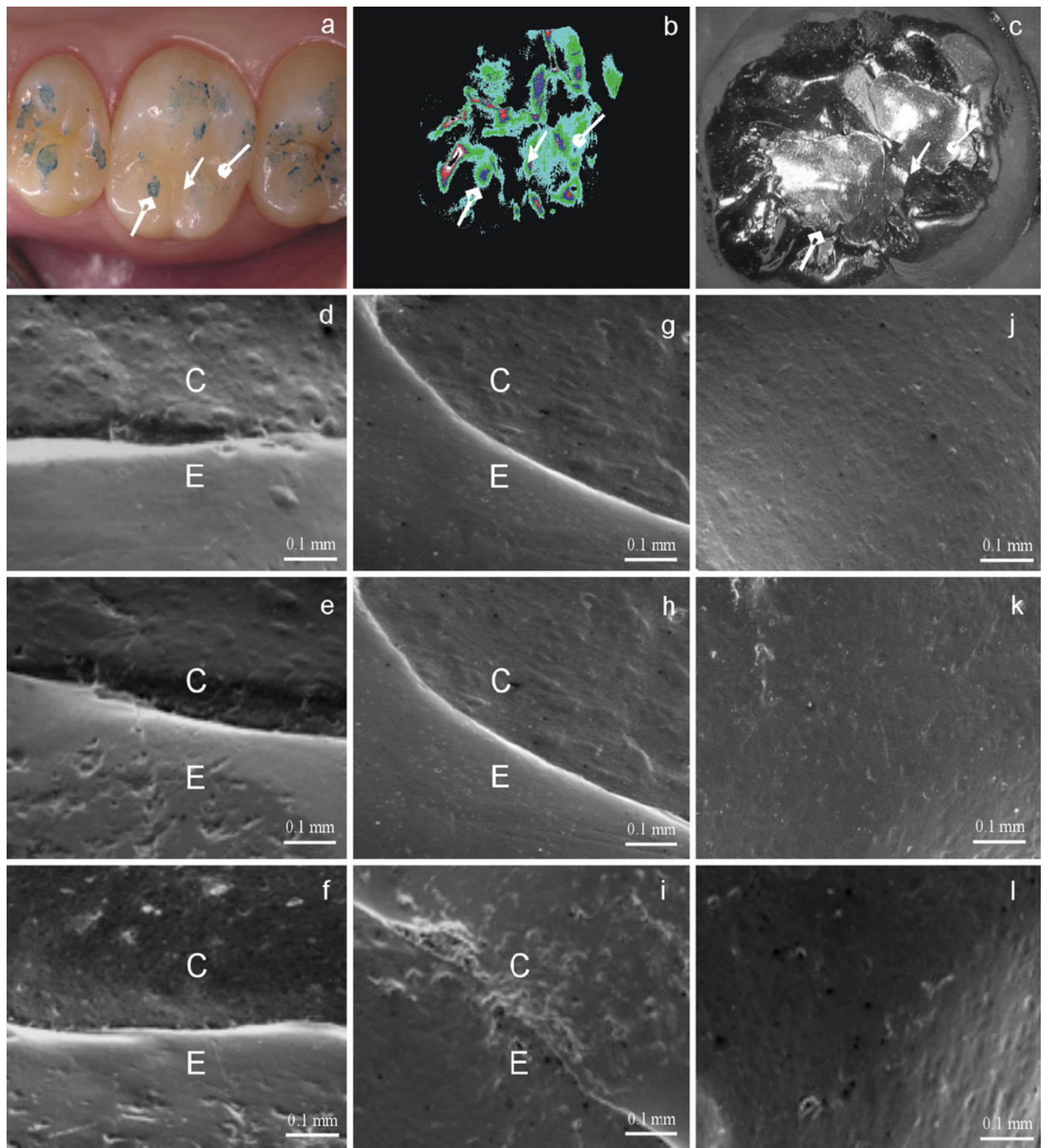

Fig. 6 A representative nano-hybrid composite restoration. This figure includes a representative clinical picture (a), difference image (b) and SEM photomicrographs (c-l) of wear spots in a nano-hybrid composite restoration over the study period. a Clinical, occlusal view of a Tetric EvoCeram restoration in 26 with registered wear spots. $\rightarrow=$ light occlusal contact area; $\longrightarrow=$ heavy OCA; $\longrightarrow=$ contact-free occlusal area. b Difference image at 36 months is shown to enable a better differentiation of the wear spots. c Micro-morphological overview at 6 months under magnification $(\times 15)$, higher magnification $(\times 150)$ of heavy OCA at 12 (d), 24 (e) and 36 months (f); light OCA at 12 (g), 24 (h) and 36 months (i); CFOA at 12 (j), 24 (k) and 36 months (l) 

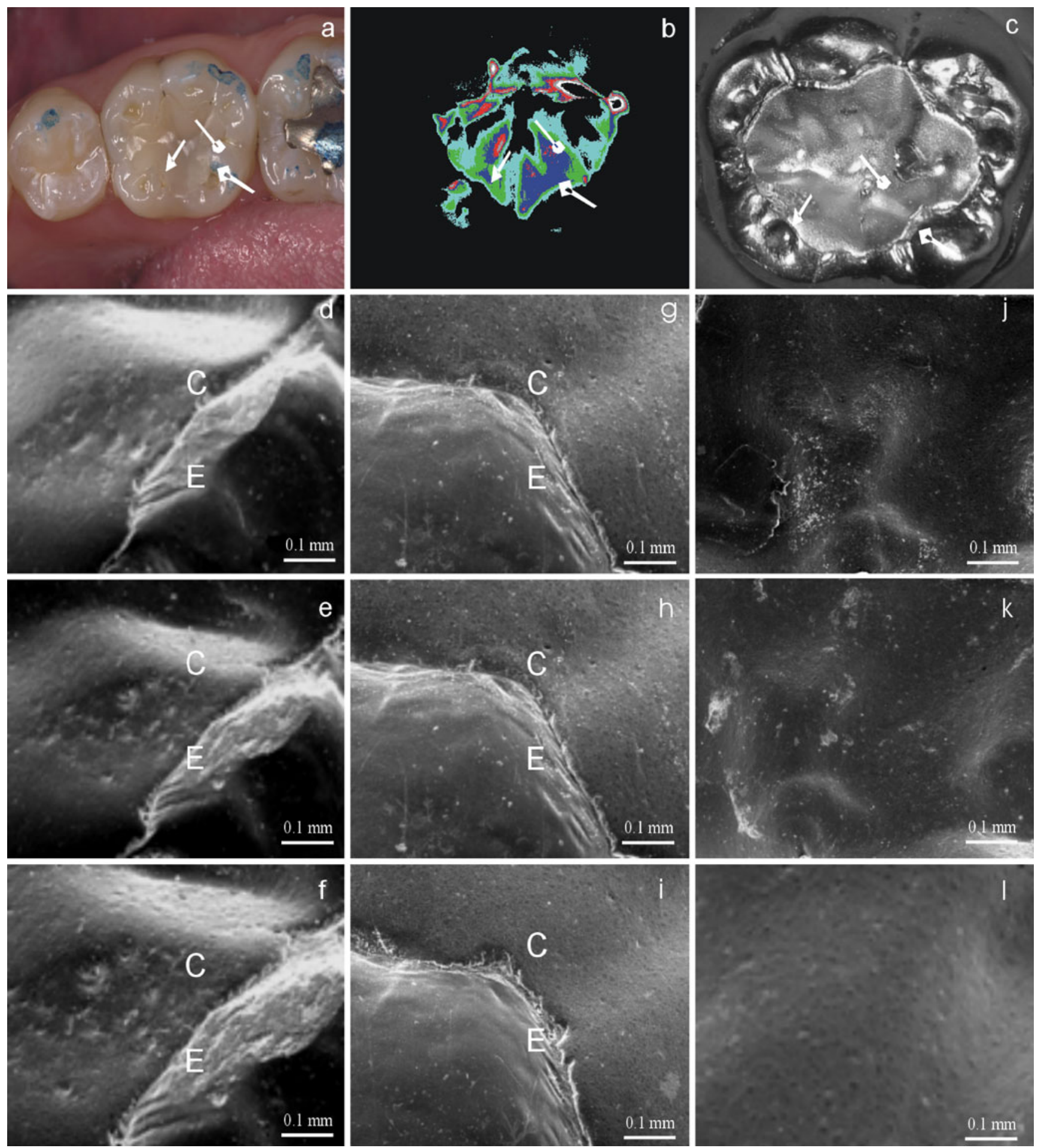

Fig. 7 A representative micro-filled hybrid composite restoration. This figure includes a representative clinical picture (a), difference image (b) and SEM photomicrographs (c-l) of wear spots in a microfilled hybrid composite restoration over the study period. a Clinical, occlusal view of a Gradia Direct Posterior restoration in 36 with registered wear spots. $\longrightarrow=$ light occlusal contact area; $\longrightarrow$ = heavy
OCA $\longrightarrow$ = contact-free occlusal area. b Difference image at 36 months is shown to enable a better differentiation of the wear spots. c Micro-morphological overview at 6 months under magnification $(\times 15)$, higher magnification $(\times 150)$ of heavy OCA at $12(\mathbf{d}), 24(\mathbf{e})$ and 36 months (f); light OCA at 12 (g), 24 (h) and 36 months (i); CFOA at $12(\mathbf{j}), 24(\mathbf{k})$ and 36 months (l) 
their light OCAs showed less surface roughness after 3 years of clinical service.

Conflict of interest statement The authors declare that they have no conflict of interest.

Open Access This article is distributed under the terms of the Creative Commons Attribution Noncommercial License which permits any noncommercial use, distribution, and reproduction in any medium, provided the original author(s) and source are credited.

\section{References}

1. Hickel R, Manhart J (2001) Longevity of restorations in posterior teeth and reasons for failure. J Adhes Dent 3:45-64

2. Lambrechts P, Debels E, Van Landuyt K, Peumans M, Van Meerbeek B (2006) How to simulate wear? Overview of existing methods. Dental Mater 22:693-701

3. Lambrechts P, Vuylsteke M, Vanherle G, Davidson CL (1984) Quantitative evaluation of the wear resistance of posterior dental restorations. A new three-dimensional measuring technique. J Dent 12:252-267

4. Lambrechts P, Braem M, Vuylsteke-Wauters M, Vanherle G (1989) Quantitative in vivo wear of human enamel. J Dent Res 68:1752-1754

5. Condon JR, Ferracane JL (1997) In vitro wear of composite with varied cure, filler level, and filler treatment. J Dent Res 76:1405-1411

6. Gaengler P, Hoyer I, Montag R, Gaebler P (2004) Micromorphological evaluation of posterior composite restorations - a 10-year report. J Oral Rehabil 31:991-1000

7. Jensen ME, Chan DCN (1985) Polymerization shrinkage and microleakage. In: Vanherle G, Smith DC (eds) Posterior composite resin dental restorative materials. Peter Szulc, Utrecht, pp 243-262

8. Lutz F, Krejci I, Imfeld T, Elzer A (1991) Hydrodynamisches verhalten der dentin-tubulus-flussigkeit unter okklusaler-belastung. Schweiz Monatsschr Zahnmed 101:24-30

9. Pashley DH (1985) Dentin-predentin complex and its permeability: physiologic overview. J Dent Res 64(Spec Issue):613-620

10. Perdigao J, Geraldeli S, Hodges JS (2003) Total-etch versus selfetch adhesive: effect on postoperative sensitivity. J Am Dent Assoc 134:1621-1629

11. Krämer N, Reinelt C, Richter G, Petschelt A, Frankenberger R (2009) Nanohybrid vs. fine hybrid composite in class II cavities: clinical results and margin analysis after four years. Dent Mater 25:750-759

12. Bottenberg P, Alaerts M, Keulemans F (2007) A prospective randomised clinical trial of one bis-GMA-based and two ormocerbased composite restorative systems in class II cavities: three-year results. J Dent 35:163-171
13. Manhart J, Neuerer P, Scheibenbogen-Fuchsbrunner A, Hickel R (2000) Three-year clinical evaluation of direct and indirect composite restorations in posterior teeth. J Prosthet Dent 84:289-296

14. Nikaido T, Kunzelmann KH, Chen H, Ogata M, Harada N, Yamaguchi S, Cox CF, Hickel R, Tagami J (2002) Evaluation of thermal cycling and mechanical loading on bond strength of a self-etching primer system to dentin. Dent Mater 18:269275

15. Feilzer AJ, De Gee AJ, Davidson CL (1987) Setting stress in composite resin in relation to configuration $\mathrm{C}$ in the restoration. $\mathrm{J}$ Dent Res 66:1636-1639

16. Manhart J, Chen HY, Hamm G, Hickel R (2004) Review of the clinical survival of direct and indirect restorations in posterior teeth of the permanent dentition. Oper Dent 29:481-508

17. Willems G, Lambrechts P, Lesaffre E, Braem M, Vanherle G (1993) Three-year follow-up of five posterior composites: SEM study of differential wear. J Dent 21:79-86

18. Satou N, Khan AM, Satou K, Satou J, Shintani H, Wakasa K, Yamaki M (1992) In-vitro and in-vivo wear profile of composite resins. J Oral Rehabil 19:31-37

19. Suputtamongkol K, Anusavice KJ, Suchatlampong C, Sithiamnuai P, Tulapornchai C (2008) Clinical performance and wear characteristics of veneered lithia-disilicate-based ceramic crowns. Dent Mater 24:667-673

20. Heintze SD, Cavalleri A, Forjanic M, Zellweger G, Rousson V (2006) A comparison of three different methods for the quantification of the in vitro wear of dental materials. Dent Mater 22:1051-1062

21. Gernhardt CR, Salhab J, Schaller HG (2001) Die Zugfestigkeit verschiedener Dentinhaftvermittler auf trockenem und perfundiertem Dentin. Dtsch Zahnärztl Z 56:467-471

22. Hara AT, Amaral CM, Pimenta LA, Sinhoreti MA (1999) Shear bond strength of hydrophilic adhesive systems to enamel. Am J Dent 12:181-184

23. Moll K, Gartner T, Haller B (2002) Effect of moist bonding on composite/enamel bond strength. Am J Dent 15:85-90

24. Castro RAL, Chevitarese O, de Souza IPR (2003) Action of titanium tetraflouride on occlusal human enamel in situ. Fluoride 36:252-262

25. Patrick M (2006) Intertooth and intrafacet dental microwear variation in an archaeological sample of modern humans from the Jordan Valley. Am J Phys Anthropol 129:39-44

26. Ryan AS (1979) Wear striation direction on primate teeth: a scanning electron microscope examination. Am J Phys Anthropol 50:155-168

27. Teaford MF (1988) A review of dental microwear and diet in modern mammals. Scanning Microsc 2:1149-1166

28. Kaidonis JA (2008) Tooth wear: the view of the anthropologist. Clin Oral Invest 12:S21-S26

29. Every RG (1972) A new terminology for mammalian teeth: founded on the phenomenon of thegosis. Parts $1 \& 2$. Pegasus, Christchurch 